\title{
Erratum: "On the Role of Spectral Diffusion in Single-Molecule Spectroscopy" \\ [Phys. Solid State 42 (3), 477 (2000)]
}

V. V. Palm, K. K. Rebane, and A. Zabrodskiǔ

Institute of Physics, Academy of Sciences of Éstonia, Riia 142, Tartu, EE2400 Éstonia

e-mail: rebanek@fi.tartu.ee

The editorial board of the journal Fizika tverdogo tela apologizes for indicating A. Zabrodskiu as an author of the article "On the Role of Spectral Diffusion in Single-Molecule Spectroscopy" published in Phys. Solid State 42 (3), 477 (2000).

The authors of this article are V. V. Palm and K. K. Rebane. 